\title{
DOSE DE INJÚRIA ECONÔMCA DO HERBICIDA CYANAZINE NA CULTURA DO MILHO
}

\author{
Ribas A. Vidal' ${ }^{1}$, Vitor Spader ${ }^{2}$, Nilson G. Fleck ${ }^{1}$ e Aldo Merotto Jr. ${ }^{2}$ \\ 'Eng ${ }^{\circ}$. Agrônomo, PhD, Professor. Departamento de Plantas de Lavoura, Faculdade de Agronomia, UFRGS. Caixa Postal 776. Porto \\ Alegre, RS 91501-970 ribas.vidal@ufrgs.br \\ ${ }^{2} \mathrm{Eng}^{\mathrm{o}}$. Agrônomo, M.Sc. UFRGS.
}

\begin{abstract}
RESUMO
A tolerância de plantas de milho ao herbicida cyanazine é variável em função dos estágios de desenvolvido da cultura. Um experimento foi conduzido em campo, na UFRGS, em Eldorado do Sul, RS, com os objetivos de avaliar a seletividade de cyanazine aspergido nos diferentes estágios de desenvolvimento vegetativo do milho e com diferentes doses do herbicida, e verificar a resposta econômica de sua toxicidade na cultura. O milho híbrido AG501 foi implantado no sistema de semeadura direta, numa área com controle prévio das plantas daninhas com herbicida pré-emergente. Os tratamentos foram organizados num esquema fatorial representado por doses de cyanazine $(0,0,2,0$ e 2,5 kg/ha) e pelos estádios de desenvolvimento vegetativo do milho $\left(\mathrm{V}_{3}, \mathrm{~V}_{6} \mathrm{e} \mathrm{V}_{9}\right.$, indicando $3,6 \mathrm{e} 9$ folhas expandidas, respectivamente). O delineamento experimental foi o de blocos casualizados com quatro repetições. A seletividade do cyanazine para a cultura do milho diminui a partir do estádio de 6 folhas expandidas $\left(\mathrm{V}_{6}\right)$ e com o incremento da dose além de $2,0 \mathrm{~kg} / \mathrm{ha}$. A dose de injúria econômica, ou seja, a dose de cyanazine onde o benefício do controle de ervas se iguala à perda de rendimento de grilos de grãos devido à injúria à cultura, se reduz com a diminuição do prejuízo econômico causado pelas infestantes e com o aumento do preço da cultura. Esses resultados indicam que quando a infestação de plantas daninhas for pouco superior ao nível de dano econômico, a injúria do herbicida à cultura pode causar mais impacto econômico do que em infestações elevadas.
\end{abstract}

Palavra chave: estádio de desenvolvimento, planta daninha, seletividade.

\section{ABSTRACT \\ Dose of economical injury of cyanazine in corn}

The tolerance of the corn crop to the herbicide cyanazine depends on the growth stage of the crop. An experiment was conducted in Eldorado do Sul, RS, Brazil, to evaluate the selectivity of cyanazine applied at different rates on corn, and at different growth stages, to estimate the economic impact of crop injury caused by the herbicide. The corn hybrid AG 501 was planted on a no-till system where the weed control was performed with preemergence herbicides. Treatments tested were combinations of cyanazine (rates of $0.0,2.0$ and $2.5 \mathrm{~kg} / \mathrm{ha}$ ) at different growth stages $\left(\mathrm{V}_{3}, \mathrm{~V}_{6}\right.$ and $\left.\mathrm{V}_{9}\right)$. Cyanazine selectivity decreases after the corn crop reaches the six leaf stage, and with herbicide rates superior to $2.0 \mathrm{~kg} / \mathrm{ha}$. The rate of economic injury, that is, the herbicide rate which the benefit of the weed control is equivalent to the yield loss due to weed competition, reduces with the reduction of the economic impact of the weed on the crop, and with increased corn price. These results suggest that when the weed infestation is almost above the weed economic threshold, the economic impact of the herbicide injury is higher than at high weed densities.

Key words: growth stage, herbicide, selectivity, weed. 


\section{INTRODUÇÃO}

O controle de plantas daninhas após a emergência, permite maior flexibilidade na escolha do herbicida e da dose a serem aplicados, em função das espécies presentes e da infestação da área. Com herbicidas aplicados em pós emergência é possível fazer o controle somente nas manchas, onde a infestação oferece possibilidade de dano à cultura, diminuindo a quantidade de herbicida aplicado na lavoura e o custo do controle de plantas daninhas. No entanto, quando a aplicação é realizada em cobertura sobre as plantas daninhas e a cultura, os herbicidas utilizados devem ser seletivos para a cultura.

Um dos herbicidas mais utilizados para controle de plantas daninhas em pós emergência na cultura do milho é cyanazine, que pertence ao grupo químico das triazinas. Os herbicidas deste grupo bloqueiam a atividade da quinona $\mathrm{Q}_{b}$ na proteina $\mathrm{D}_{1}$ nas membranas do tilacóide no cloroplasto, inibindo o transporte de elétrons no fotossistema II, afetando as moléculas de clorofila e interrompendo o processo fotossintético das plantas sensíveis. Com isso, ocorre formação de radicais livres, que provocam a peroxidação de lipídios e a destruição de membranas das células e organelas, resultando na morte das plantas (Vidal \& Merotto Jr., 2001).

O milho é tolerante aos herbicidas deste grupo porque possui enzimas que os metabolizam, transformando-os em compostos não fitotóxicos. As principais enzimas responsáveis pela tolerância do milho aos herbicidas são a glutationa s-transferase (GST) e o citocromo $\mathrm{P}_{450}$ (cit $\mathrm{P}_{450}$ ) (Gronwald, 1994). A GST se liga aos locais eletrofilicos do herbicida, formando conjugados de glutationa, os quais não tem ação fitotóxica (Shimabukuro, 1985), e o cit $\mathrm{P}_{450}$ catalisa reações de monoxigenação evitando efeitos destes herbicidas nas plantas (Donaldson \& Luster, 1991).

A tolerância do milho ao herbicida cyanazine varia com o estádio de desenvolvimento das plantas (Kern et al., 1975b,c; Schuh \& Harvey, 1989), com a dose aplicada (Kern et al., 1975a; Almeida et al., 1982; McMullan \& Blackshaw, 1995) e com as condições climáticas durante e após o tratamento (Kern et al., 1975b; Schuh \& Harvey, 1989). A máxima seletividade de cyanazine aplicada em pós emergência nas plantas de milho foi obtida quando a cultura apresentava menos de cinco folhas desenvolvidas (Kern et al., 1975a). Porém, plantas de milho tratadas com cyanazine até o estádio de três a quatro folhas apresentaram clorose foliar e redução de estatura, embora o rendimento de grãos não tenha sido afetado (Almeida et al., 1982). De acordo com os autores, a mistura de surfactante à calda aumentou a injúria do herbicida no milho, reduzindo o rendimento de grãos.

A redução da temperatura do ar de $12^{\circ} \mathrm{C}$ para $9^{\circ} \mathrm{C}$ e o aumento da umidade relativa do ar após a aplicação de cyanazine também aumentaram substancialmente a injúria às plantas de milho) Schuh \& Harvey, 1989). De acordo com Kern et al. (1975a), baixa temperatura do ar diminui o metabolismo, enquanto alta umidade relativa do ar favorece a absorção e a translocação do herbicida nos vegetais. Plantas de milho tratadas com cyanazine na dose de $2,4 \mathrm{~kg} / \mathrm{ha}$, nos estádios $\mathrm{V}_{6} \mathrm{e}$ $\mathrm{V}_{7}$, aumentaram em $10 \%$ a injúria foliar e a redução do vigor, em relação às plantas tratadas com $1,7 \mathrm{~kg} /$ ha nos mesmos estádios de desenvolvimento (Kern et al., 1975a).

Normalmente, a decisão de aplicação dos herbicidas é tomada de forma empírica, com base nas observações visuais da área. Teoriza-se que a tomada de decisão para controle de plantas daninhas deveria ser baseada em fatores biológicos e econômicos. Esses fatores são englobados no conceito de nível de dano econômico, definido como a densidade limite de plantas daninhas, a partir da qual ocorre danos à cultura numa magnitude que justifique economicamente a aplicação do herbicida pós emergente na dose recomendada (Deen et al., 1993). O nível de dano econômico de Braschiaria Plantaginea na cultura do milho se situa entre 1 e 10 plantas $/ \mathrm{m}^{2}$ (Spader, 2000). Nessas baixas densidades, é reduzido o impacto econômico das plantas daninhas sobre a cultura. Como a injúria do herbicida à cultura pode reduzir o seu rendimento de grãos, é importante conhecer o potencial de dano que o herbicida em questão poderá oferecer à cultura, nas condições em que será aplicado e, assim, possibilitar a tomada de decisão com maior segurança sobre a viabilidade econômica do controle de plantas daninhas.

Nesse trabalho é testado o conceito de dose de injúria econômica (DIE), definido como a máxima dose (percentagem em relação à dose recomendada em rótulo) a ser utilizada, em que o benefício do controle de plantas daninhas pelo menos se iguala à perda de rendimento de grãos causada pela fitotoxicidade à cultura (Spader \& Vidal, 2001). Assim, os objetivos desse estudo foram avaliar a seletividade do herbicida cyanazine aspergido em três doses em três estádios de desenvolvimento vegetativo e estima a sua DIE na cultura do milho.

\section{MATERIAL E MÉTODOS}

O experimento foi conduzido em campo durante a estação de crescimento 1998/99, em área da Estação Experimental Agronômica da Universidade Federal do Rio Grande do Sul (EEA/UFRGS), localizada em Eldorado do Sul, RS. O solo da área experimental é classificado como podzólico vermelho escuro distrófico, com $38 \%$ de argila, $\mathrm{pH}$ em água 5,8, matéria orgânica $2,2 \% ; 8 \mathrm{mg} / \mathrm{dm}^{3}$ de fósforo e $260 \mathrm{mg} / \mathrm{dm}^{3}$ de potássio.

O milho híbrido AG 5011 foi semeado no dia 8 de outubro de 1998, no sistema de semeadura direta, em sucessão à aveia preta (Avena strigosa). A adubação do milho foi realizada nas linhas de semeadura com $600 \mathrm{~kg} / \mathrm{ha}$ da fórmula NPK 5 20-20. Realizou-se adubação nitrogenada de cobertura com 100 e $150 \mathrm{~kg} / \mathrm{ha}$ de $\mathrm{N}$ aos 20 e 40 dias após a emergência, quando o milho se apresenta nos estádios $\mathrm{V}_{4}$ e $\mathrm{V}_{8}$ (quatro e oito folhas completamente expandidas), respectivamente. 
O controle de plantas daninhas foi realizado com herbicidas pré emergentes (atrazine + metolachlor nas doses de $700+1050 \mathrm{~g} / \mathrm{ha}$ ), aplicados com pulverizador tratorizado. As plantas daninhas que emergiram durante o ciclo do milho foram eliminadas com capinas. Os tratamentos foram organizados num esquema bifatorial, onde o fator $\mathrm{A}$ foram as doses do herbicidas cyanazine $(0,2,0$ e $2,5 \mathrm{~kg} / \mathrm{ha})$ e fator B os estádios de desenvolvimento vegetativo do milho $\left(\mathrm{V}_{3}, \mathrm{~V}_{6}\right.$ e $\left.\mathrm{V}_{9}\right)$. O delineamento experimental utilizado foi o de blocos casualizados, com quatro repetições. $\mathrm{O}$ tamanho das unidades experimentais foi de $8,0 \times 3,2 \mathrm{~m}$, contendo quatro fileiras de milho, espaçadas de $0,8 \mathrm{~m}$ e com 5,6 plantas por metro, perfazendo uma população de 70.000 plantas/ha após o desbaste, realizado aos 10 dias após a emergência (DAE).

As aplicações do herbicida foram realizadas com pulverizador costal pressurizaod com gás carbônico $\left(\mathrm{CO}_{2}\right)$, equipado com barra de 2,0 m e bicos tipo leque 80.03 , mantendo-se a pressão constante em $1,5 \mathrm{kgf} / \mathrm{cm}^{2}$, e vazão equivalente a 220 1/ha. A temperatura e a umidade relativa do ar durante cada aplicação foram de, respectivamente, $28^{\circ} \mathrm{C}$ e $72 \%$, no estádio $\mathrm{V}_{3}, 25^{\circ} \mathrm{Ce} 80 \%$ no estádio $\mathrm{V}_{6}$ e, $27^{\circ} \mathrm{C}$ e $75 \%$ no estádio $\mathrm{V}_{9}$. Aos 5 dias após a semeadura foi feita uma irrigação por aspersão, de $20 \mathrm{~mm}$. Efetuou-se outras irrigações por aspersão, nos períodos em que a precipitação pluvial foi insuficiente para suprir a exigência da cultura, até o estágio de maturação fisiológica do milho.

Avaliou-se a injúria nas plantas do milho através da estatura de planta, número de espigas por planta, grãos por espiga, peso de mil grãos e rendimento de grãos de milho. As avaliações foram feitas nas duas linhas centrais, descontando-se 1,0 m em cada extremidade, perfazendo 9,6 $\mathrm{m}^{2}$ de área útil. Os dados foram submetidos à análise de variância pelo teste $\mathrm{Fe}$ ao teste de Tukey, ambos ao nível de significância de $5 \%$ de probabilidade.

Foram feitas análises de regressão entre rendimento de grãos do milho e dose de herbicida em cada estádio de desenvolvimento da cultura. Essas regressões foram feitas com auxílio do programa computacional "Origin". As declividades das curvas (D) divididas pela intercecção no eixo Y (A) ajustadas em cada época de aplicação foram utilizadas para estimar a dose de injúria econômica (DIE) do herbicida cyanazine aplicado em pós emergência no milho, conforme a Equação 1.

$$
\mathrm{DIE}=\mathrm{DE} /[10000 *(\mathrm{D} / \mathrm{A}) *(\mathrm{P} / 1000)] \quad(\text { Equação } 1)
$$

Para cálculo da DIE considerou-se o preço do milho (P) variando na faixa entre $R \$ 100,00$ e $R \$ 300,00$ por tonelada e estimou-se o dano causado pelas plantas daninhas (DE) entre $\mathrm{R} \$ 10,00$ e R $\$ 300,00$ por hectare (Spader, 2000; Spader \& Vidal, 2001).

\section{RESULTADOS E DISCUSSÃO}

Plantas de milho tratadas com cyanazine, em ambos os estádios tratados, apresentaram sintomas de injúrias, iniciando com clorose foliar e culminando com necrose, principalmente nas bordas e pontas das folhas jovens.

As variáveis percentagens de plantas sem espigas e números de espigas por planta não foram afetadas pelos tratamentos herbicidas. Em média, 5\% das plantas foram estéreis e o número médio de espigas foi de uma por planta.

As plantas tratadas com a maior dose de cyanazine apresentaram menor estatura e menor número de grãos por espiga do que aquelas não tratadas, na média das três épocas de aplicação (Tabela 1) kern et al. (1975a,c) também verificaram redução da estatura das plantas tratadas com cyanazine, porém, os sintomas foram observados somente nos tratamentos realizados a partir do estádio de desenvolvimento $\mathrm{V}_{4}$.

$\mathrm{O}$ número de grãos formados por espiga diminui nas plantas tratadas com a maior dose de cyanazine em comparação com aquelas que não foram aspergidas com o herbicida (Tabela 1). Para essa variável, não houve diferença entre as épocas de aplicação do herbicida.

O peso de grão diminui nas plantas tratadas com a maior dose de cyanazine em comparação com aquelas que não foram aspergidas com o herbicida (Tabela 1). Além disso, para a variável peso de grão, na média das doses testadas, ocorreu maior efeito do herbicida nas plantas tratadas no estádio $\mathrm{V}_{9}$ em relação às tratadas no estádio $V_{3}$. Não houve diferença entre os tratamentos testados nos estádios $V_{3}$ e $V_{6}$ ou nos estádios $\mathrm{V}_{6} \mathrm{e} \mathrm{V}_{9}$ (Tabela 1 ).

$O$ rendimento de grãos diminuiu nas plantas tratadas com a maior dose de cyanazine em comparação com aquelas que não foram aspergidas com o herbicida (Tabela 1). Para essa variável, na média das doses tratadas, ocorreu maior efeito do herbicida nas plantas tratadas no estádio $V_{9}$ em relação às tratadas no estádio $V_{3}$. Não houve diferença entre os tratamentos testados nos estádios $\mathrm{V}_{3} \mathrm{e} \mathrm{V}_{6}$ ou nos estádios $\mathrm{V}_{6} \mathrm{e} \mathrm{V}_{9}$. Estes resultados concordam com os obtidos por Kern et al. (1975a,c), os quais mostraram que o rendimento de grãos de milho diminuiu quando as plantas foram tratadas com cyanazine a partir do estádio de cinco folhas desenvolvidas. As plantas tratadas nos estádios $\mathrm{V}_{6} \mathrm{e} \mathrm{V}_{9}$ provavelmente tiveram maior quantidade de folhas afetadas pelo herbicida do que aquelas tratadas no estádio $\mathrm{V}_{3}$. Isso indica que as plantas tratadas no estádio $\mathrm{V}_{3}$ tiveram maior número de folhas fotossinteticamente ativas, no final do período de emissão destas estruturas, pois as folhas que não estavam exteriorizadas durante a aspersão do herbicida provavelmente não foram afetadas pelo mesmo. Almeida et al. (1982) observaram que plantas de milho tratadas com este herbicida nos estádios de desenvolvimento de três e quatro folhas, apresentaram redução do tamanho de espiga e do rendimento de grãos.

A cyanazine é translocada nos vegetais via xilema (Kern et al., 1975b; Schuh \& Harvey, 1989), tendendo a se 
acumular nas extremidades do limbo foliar, principalmente quando a transpiração é elevada. A injúria causada por cyanazine, que resultou em clorose e necrose de parte dos tecidos, provavelmente reduziu a capacidade fotossintética das plantas de milho. A redução do fotossíntese diminui a relação fonte/ demanda e, com isso, a quantidade de fotoassimilados formados deve ter sido insuficiente para suprir a demanda de carboidratos, constituída pelos grãos em crescimento e pelas demais estruturas da planta. Isso pode ter sido responsável, ao menos em parte, pelo menor acúmulo de matéria seca nos grãos, resultando em redução do peso de grão e do rendimento de grãos, observada principalmente nas plantas tratadas no estádio $\mathrm{V}_{9}$ (Tabela 1 ).

A injúria causada por cyanazine, quando aplicado no milho a partir do estádio $\mathrm{V}_{6}$, refletiu no rendimento de grãos da cultura, reduzindo essa variável em $15 \%$, em relação à testemunha sem tratamento, na média das doses testadas.

A infestação de plantas daninhas diminui a produtividade da cultura, reduzindo o lucro obtido com a produção, de acordo com o valor de mercado do produto colhido. Porém, a injúria causada pelo herbicida pode comprometer, em parte, o benefício do controle de infestantes. Isso justifica o ajuste da dose do produto, de forma que os danos causados pela doses aplicada na cultura não provoquem perdas no rendimento maiores do que a infestação de ervas presentes na lavoura.

A declividade da reta obtida na regressão entre dose, na média dos estádios $\mathrm{V}_{6} \mathrm{eV}_{9}$, e rendimento da cultura foi de $5,73 \times 10-5$. Esse valor foi utilizado na Equação 1 e os resultados de DIE são apresentados na Tabela 2. Verifica-se que a dose de cyanazine que atingiu o nível de injúria econômica na cultura do milho, quando aplicada a partir do estádio V6, variou entre 2 e $100 \%$ da dose máxima de rótulo.

Essa dose varia de acordo com o prejuízo que as ervas podem provocar na cultura e com o preço previsto para o milho. O prejuízo causado pela maioria das espécies de plantas daninhas, na cultura do milho, em situação de alta infestação, normalmente é superior a 300 reais/ha (Vidal \& Merotto Jr., 2001). Neste caso, dificilmente a injúria causada

Tabela 1. Estatura de planta, número de grãos por espiga, peso de mil grãos e rendimento de grãos de milho submetido à aplicação de cyanazine, em três doses e em três estádios de desenvolvimento vegetativo. EEA/UFRGS, Eldorado do Sul, RS. 1998/99.

\begin{tabular}{|c|c|c|c|c|}
\hline \multirow{2}{*}{$\begin{array}{l}\text { Dose } \\
\text { (kg/ha) }\end{array}$} & \multicolumn{4}{|c|}{ 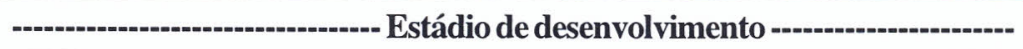 } \\
\hline & $\mathbf{V}^{1}$ & V6 & V9 & Média \\
\hline \multicolumn{5}{|c|}{ Estatura de planta $(\mathrm{cm})$} \\
\hline 0,0 & 187 & 189 & 188 & $188 \mathbf{a}^{2}$ \\
\hline 2,0 & 183 & 182 & 175 & $180 \mathrm{ab}$ \\
\hline$\underline{2,5}$ & 178 & 177 & 174 & $176 \mathrm{~b}$ \\
\hline Médias & $182 \mathrm{~A}$ & $182 \mathrm{~A}$ & 179 & \\
\hline $\mathrm{CV}(\%)$ & & & & \\
\hline
\end{tabular}

\begin{tabular}{|c|c|c|c|c|}
\hline \multicolumn{5}{|c|}{ Grãos por espiga (nº) } \\
\hline 0,0 & 437 & 462 & 460 & $453 a$ \\
\hline 2,0 & 436 & 423 & 409 & $422 \mathrm{ab}$ \\
\hline 2,5 & 437 & 413 & 396 & $415 b$ \\
\hline Médias & $436 \mathrm{~A}$ & $432 \mathrm{~A}$ & $421 \mathrm{~A}$ & \\
\hline $\mathrm{CV}(\%)$ & & 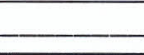 & & \\
\hline \multicolumn{5}{|c|}{ Peso de mil grãos (g) } \\
\hline 0,0 & 320 & 317 & 315 & $317 \mathbf{a}$ \\
\hline 2,0 & 315 & 306 & 290 & $303 \mathrm{ab}$ \\
\hline 2,5 & 312 & 285 & 280 & 292 b \\
\hline Médias & $315 \mathrm{~A}$ & $302 \mathrm{AB}$ & 295 B & \\
\hline $\mathrm{CV}(\%)$ & \multicolumn{4}{|c|}{6,1} \\
\hline \multicolumn{5}{|c|}{ Rendimento de grãos (kg/ha) } \\
\hline 0,0 & 9320 & 9245 & 9283 & 9282 a \\
\hline 2,0 & 9039 & 8755 & 8015 & $8603 \mathrm{~b}$ \\
\hline$\underline{2,5}$ & 8709 & 8075 & 7598 & 8127 b \\
\hline Médias & $9022 \mathrm{~A}$ & $8691 \mathrm{AB}$ & 8298 B & \\
\hline CV (\%) & \multicolumn{4}{|c|}{8,3} \\
\hline
\end{tabular}

${ }_{1} \mathrm{~V}_{3}, \mathrm{~V}_{6}$ e $\mathrm{V}_{9}$ referem-se às plantas de milho tratadas quando apresentavam 3, 6 e 9 folhas totalmente expandidas, respectivamente.

2 Médias seguidas pela mesma letra, minúscula nas colunas e maiúscula nas linhas, não diferem significativamente pelo teste de Tukey $(\mathrm{P}>0,05)$. 
Dose de injúria econômica do herbicida cyanazine na cultura do milho

Tabela 2. Dose de injúria econômica do herbicida cyanazine aplicado a partir do estádio de desenvolvimento com seis folhas expandidas $\left(\mathrm{V}_{6}\right)$ na cultura do milho EEA/UFRGS, Eldorado do Sul, RS. 1998/99.

\begin{tabular}{|c|c|c|c|c|c|c|}
\hline \multirow{3}{*}{$\begin{array}{l}\text { Prejuízo com } \\
\text { as infestantes } \\
(\mathbf{R} \$ / \mathbf{h a})\end{array}$} & \multicolumn{6}{|c|}{ Preço do milho $(\mathrm{R} \$ / \mathrm{t})$} \\
\hline & 100 & 150 & 200 & & 250 & 300 \\
\hline & \multicolumn{6}{|c|}{ \% da dose máxima de rótulo } \\
\hline 10 & 5 & 3 & 3 & 2 & & 2 \\
\hline 50 & 24 & 16 & 12 & 9 & & 8 \\
\hline 100 & 46 & 31 & 24 & 19 & & 16 \\
\hline 150 & 70 & 46 & 35 & 28 & & 24 \\
\hline 200 & 85 & 62 & 46 & 37 & & 31 \\
\hline 250 & 94 & $\pi$ & 58 & 46 & & 39 \\
\hline 300 & 100 & 85 & 70 & 56 & & 46 \\
\hline
\end{tabular}

pelo herbícida na cultura seria maior do que o dano das ervas, justificando a aplicação do herbicida na dose recomendada no rótulo. Contudo, quando a infestação de plantas daninhas estiver próxima do limite de dano econômico (baixa infestação), o prejuízo econômico das ervas será baixo e, nesse caso, maior poderá ser o impacto do dano do herbicida no rendimento econômico da cultura (Tabela 2). Resultados semelhantes foram obtidos por Spader \& Vidal (2001) com o herbicida nicosulfuron na cultura milho.

Verifica-se que, em situações em que o prejuízo das ervas é pequeno e/ou quando o preço do milho é alto, a dose máxima de injúria econômica é bastante reduzida. Ressalta-se que com utilização de dose inferior a de rótulo, algumas plantas daninhas podem se tolerantes ao herbicida.

\section{CONCLUSÕES}

O herbicida cyanazine reduz o rendimento de grãos de milho quando aplicado após o estádio de desenvolvimento de seis folhas. O efeito negativo de cyanazine no rendimento de grãos de milho ocorre já na dose de $2,0 \mathrm{~kg} / \mathrm{ha}$. A injúria provocada por cyanazine à cultura de milho se reflete nos resultados econômicos do rendimento de grãos quando o prejuízo causado pelas plantas daninhas é baixo. É válido o conceito de dose de injúria econômica, ousseja, a dose do herbicida onde o benefício do controle de plantas daninhas se iguala à perda de rendimento de grãos devido a injúria às plantas cultivadas. $\mathrm{O}$ dano de injúria econômica se reduz com a redução da infestação das plantas daninhas e com o aumento do preço da cultura.

\section{LITERATURA CITADA}

ALMEIDA, F. S.; RODRIGUES, B. N.; OLIVEIRA, V. F. Controle de ervas. In: IAPAR. O milho no Paraná. Londrina: IAPAR, 1982.p. 109-140. (Circular, 29).
DEEN, W. A. WEERSINK, A.; TURVEY, C. G. et al. Weed control decision rules uncertainly. Annual Review Agricultural Economic, Palo Alto, v. 15, n. 1, p. 39-50, 1993.

GRONWALD, J. W. Resistence to photosystem II inhibiting herbicides. In: POWLES, S. B.; HOLTUM, J. A. M. Herbicides resistance in plants: biology and biochemistry. Boca Raton: CRC Press, 1994. p. 27-60.

KERN, A. D.; MEGGITT, W. F.; PENNER, D. Influence of stage of growth and adjuvants on fall panicum control in corn with cyanazine. Weed Science, Champaign, v. 23, n. 3, p. 241-245, 1975a.

KERN, A. D.; MEGGITT, W. F.; PENNER, D. Uptake, movement and metabolism of cyanazine in fall panicum, green foxtail and corn. Weed Science, Champaing, v. 23, n. 4, p. 277 282,1975 b.

KERN, A. D.; MEGGITT, W. F.; PENNER, D. Influence of soil moisture on tolerance of corn to cyanazien. Weed Science, Champaing, v. 23, n. 6, p. 522-524, 1975 c.

McMULLAN, P. M.; BLACKSHAW, R. E. Postermergence green foxtail (Setaria viridis) control in corn (Zea mays) in Western Canada. Weed Tecnology, Champaign, v. 9, n. 1, p. 37-43, 1995.

RONALDSON, R. P.; LUSTER, D. G. Multiple forms of plant cytochromes $\mathrm{P}_{450}$. Plant Physiology, Rockville, v. 96, n. 2, p. 369-374, 1991.

SCHUH, J. F; HARVEY, G. Woolly cupgrass (Eriochloa villosa) control en corn (Zea Mays) with pendimethalin combinations and cultivaton. Weed Science, Champaign, v. 9, n. 1, p. 37-43, 1995. 
Ribas A. Vidal et al.

SHIMABUKURO, R. H. Detoxication of herbicides. In: DUKE, S. O. Weed physiology. v. 1. Reproduction and ecophysiology. Boca Raton: CRC Press, 1985. P. 215240 .

SPADER, V. Avaliação bioconômica da interferência de Brachiaria plantagínea (Link.) Hitch. e de herbicidas na cultura do milho. Porto Alegre, 2000. 74p. (Disserta- ção de Mestrado). Universidade Federal do Rio Grande do Sul, 2000

SPADER, V.; VIDAL, R. A. Seletividade e dose de injúria econômica de nicosulfuron aplicado em diferentes estádios de desenvolvimento da cultura do milho. Ciência Rural, Santa Maria, v. 31, n. 6, p. 929-934, 2001.

VIDAL, R. A.; MEROTTO JR., A. Herbicidologia. Porto Alegre: Evangraf, 2001. 152p. 